\title{
Practical Considerations for the Reintroduction of Large, Terrestrial, Mammalian Predators Based on Reintroductions to South Africa's Eastern Cape Province
}

\author{
Matt W. Hayward*,1,2 ${ }^{\text {, John Adendorff }}{ }^{3}$, John O’Brien ${ }^{4,5}$, Angus Sholto-Douglas ${ }^{6}$, \\ Charlene Bissett ${ }^{5,6}$, Lucius C. Moolman ${ }^{3}$, Peter Bean ${ }^{7}$, Alan Fogarty ${ }^{8}$, Dale Howarth ${ }^{9}$, \\ Richard Slater $^{10}$ and Graham I. H. Kerley ${ }^{2}$
}

\author{
${ }^{I}$ Marie Curie Fellow, Mammal Research Institute, Polish Academy of Science, 17-230 Białowieża, Poland \\ ${ }^{2}$ Centre for African Conservation Ecology, Department of Zoology, Nelson Mandela Metropolitan University, PO Box \\ 77000, Port Elizabeth, 6031, Eastern Cape, South Africa; Visiting Fellow, School of Biological, Earth and Environ- \\ mental Science, University of New South Wales, Sydney 2051 Australia \\ ${ }^{3}$ Addo Elephant National Park, PO Box 52, Addo, 6105, Eastern Cape, South Africa \\ ${ }^{4}$ Shamwari Game Reserve, PO Box 91, Paterson, 6130, Eastern Cape, South Africa \\ ${ }^{5}$ Wildlife \& Reserve Management Research Group, Department of Zoology \& Entomology, Rhodes University, Graham- \\ stown, Eastern Cape, South Africa \\ ${ }^{6}$ Kwandwe Game Reserve, PO Box 448, Grahamstown, 6140, Eastern Cape, South Africa \\ ${ }^{7}$ Scotia Safaris, Paterson, 6130, Eastern Cape, South Africa \\ ${ }^{8}$ Kariega Game Reserve, PO Box 13900, Humewood, 6013, Eastern Cape, South Africa \\ ${ }^{9}$ Pumba Private Game Reserve, 29-10 th Avenue, Walmer, 6070, Eastern Cape, South Africa \\ ${ }^{10}$ Samara Game Reserve, Graaff Reinet
}

\begin{abstract}
The expansion of conservation estate in South Africa has seen large predators increasingly reintroduced in order to restore ecological integrity, conserve threatened species and maximise tourism. Reintroductions occurred at fenced, ecotourism sites in South Africa's Eastern Cape Province. Lion Panthera leo reintroduction began in 2000 and has been highly successful with a population of 56 currently extant in the region arising from 35 reintroduced individuals. The African wild dog Lycaon pictus population has increased to 24 from a founder population of 11 . Reintroduction of spotted hyaenas Crocuta crocuta also appears successful, although reintroductions of leopards Panthera pardus and cheetahs Acinonyx jubatus have been less successful. Here we review the successes and failures of the reintroductions that have occurred in the region and describe recommendations to assist future translocations. Ecological attributes of each species affected the success with which they were reintroduced. Soft-release techniques, adequate fencing, appropriate socioeconomic environment, the order of predator reintroduction with subordinate species released prior to dominant ones, adequate prey base and adequate monitoring all improved the success of reintroductions. Carrying capacity for large predators is unknown and continued monitoring and, we fear, intensive management will be necessary in virtually all modern day conservation areas.
\end{abstract}

Keywords: Carnivore conservation management, ecological economics, ecotourism, fencing, range expansion.

\section{INTRODUCTION}

Reintroducing species to parts of their former range where they have become extinct is one of the last measures wildlife managers can employ to conserve threatened species. Reintroduction is thus employed after conservation actions at a site have failed. Reintroduction of large predators has had a poor success rate in the past [1-4] and the overall conservation benefits in the long-term are questionable [5]. Despite carnivores being reintroduced more frequently than

*Address correspondence to this author at the Marie Curie Fellow, Mammal Research Institute, Polish Academy of Science, 17-230 Białowieża, Poland; E-mail: hayers111@aol.com expected [6], conservation managers around the world are not expending equal amounts of energy and resources attempting reintroductions of top-order predators [1].

Like much of Africa, the agricultural and economic development of South Africa led to such conservation failures through the extinction of large predators in all but the most uninhabitable areas [7], such as the tropical and sub-tropical lowveld (e.g., Kruger National Park and north-east KwaZulu-Natal) and the arid Kalahari. Since the advent of democracy in South Africa, uneconomical pastoralism in marginal lands has given way to game farming and ecotourism ventures leading to a massive increase in estate managed for conservation [8]. Wildlife has been reintroduced to these 
Table 1. Details of the large predator reintroductions that have occurred at each of the study sites. Founder population refers to the number of individuals initially reintroduced and excludes supplementary reintroductions. The 2005 estimate is a result of such supplementary reintroductions and births and deaths

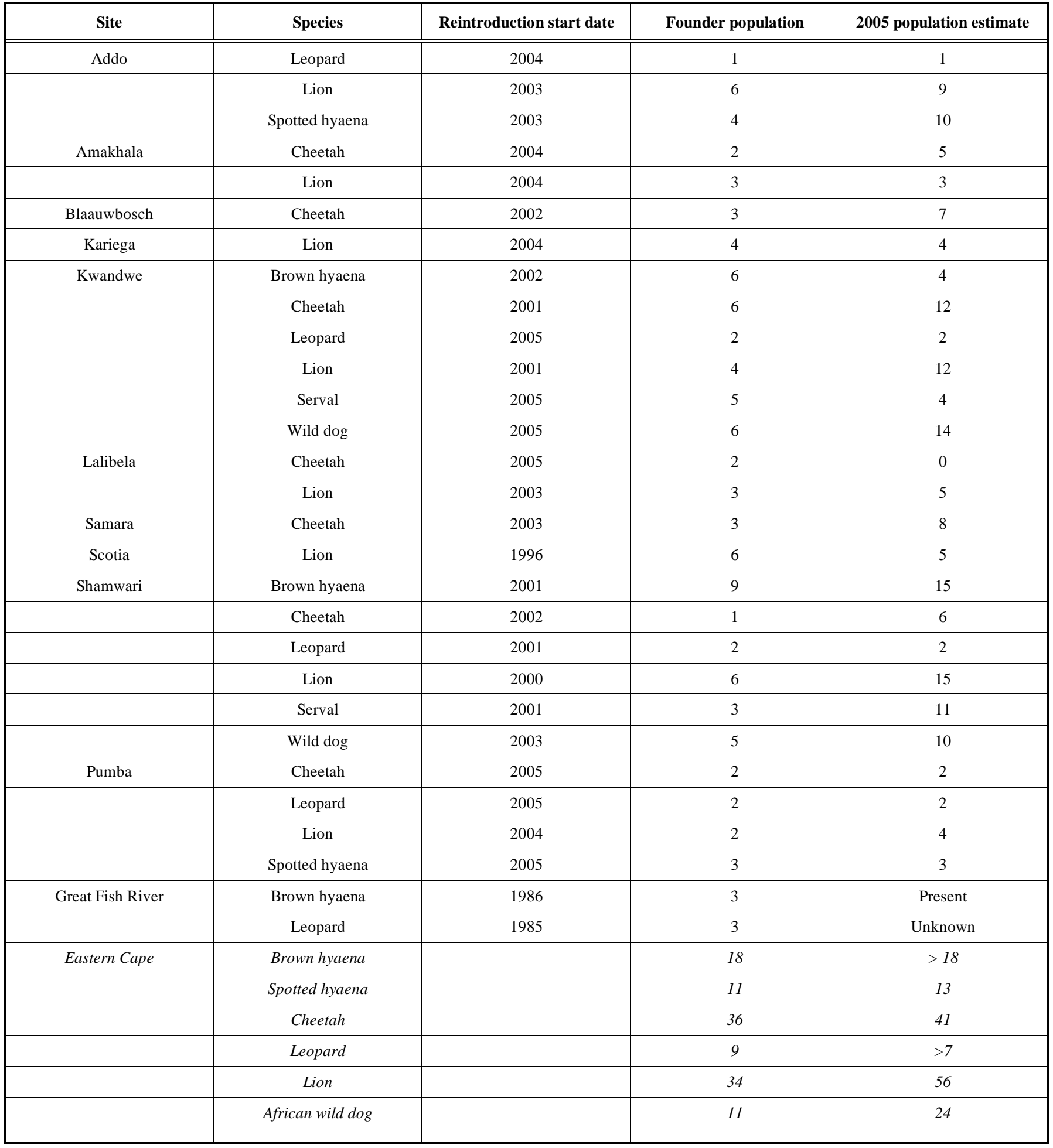

areas and this has culminated in the reintroduction of large predators [9].

It is widely recommended that the results of reintroductions be published and peer-reviewed at frequent intervals to allow other reintroduction attempts to benefit from past experiences $[1,10]$. This should be part of a continuous feed- back loop with the results of the documented evaluation leading to alterations to the existing reintroduction programme via an adaptive management strategy [10]. We selected a five-yearly reporting regime, based on expert recommendations [10], but this short-time period for the initial assessment enforced limitations in our ability to measure the success of the reintroductions [9]. Based on the only assess- 
ment criteria that was valid for the initial stages of a reintroduction programme (three year breeding programme with natural recruitment exceeding mortality), lions Panthera leo were the most successful species reintroduced to the Eastern Cape with 35 individuals reintroduced since 2000 and 49 cubs having been born leading to a 2005 population of 56 individuals (Table 1) [9]. African wild dogs Lycaon pictus have doubled to 24 by 2005, arising from the 11 founders in 2003 and supplemented with 27 pups [9]. Cheetah Acinonyx jubatus reintroductions were less successful with 36 reintroduced and at least 23 cubs being born, but only 41 surviving in 2005 [9]. Spotted hyaenas Crocuta crocuta have only been present in the Eastern Cape for two years but their numbers have increased to 13 through the birth of two cubs [9]. Reintroductions of brown hyaenas Hyaena brunnea began in 1986 and numbers have remained steady of at least 18 in 2005 [9]. The ability of leopards Panthera pardus to persist despite human persecution suggests populations are stable in the Eastern Cape with nine having been reintroduced, mostly from sites within the province, although their secretive nature meant cubs have not been observed [9].

Historically, post-release monitoring of large carnivore translocations has rarely occurred and, where it has, suggests a low success rate with the causes of failures poorly understood [11]. Several authors have concluded that the factors affecting translocation success of large carnivores are too

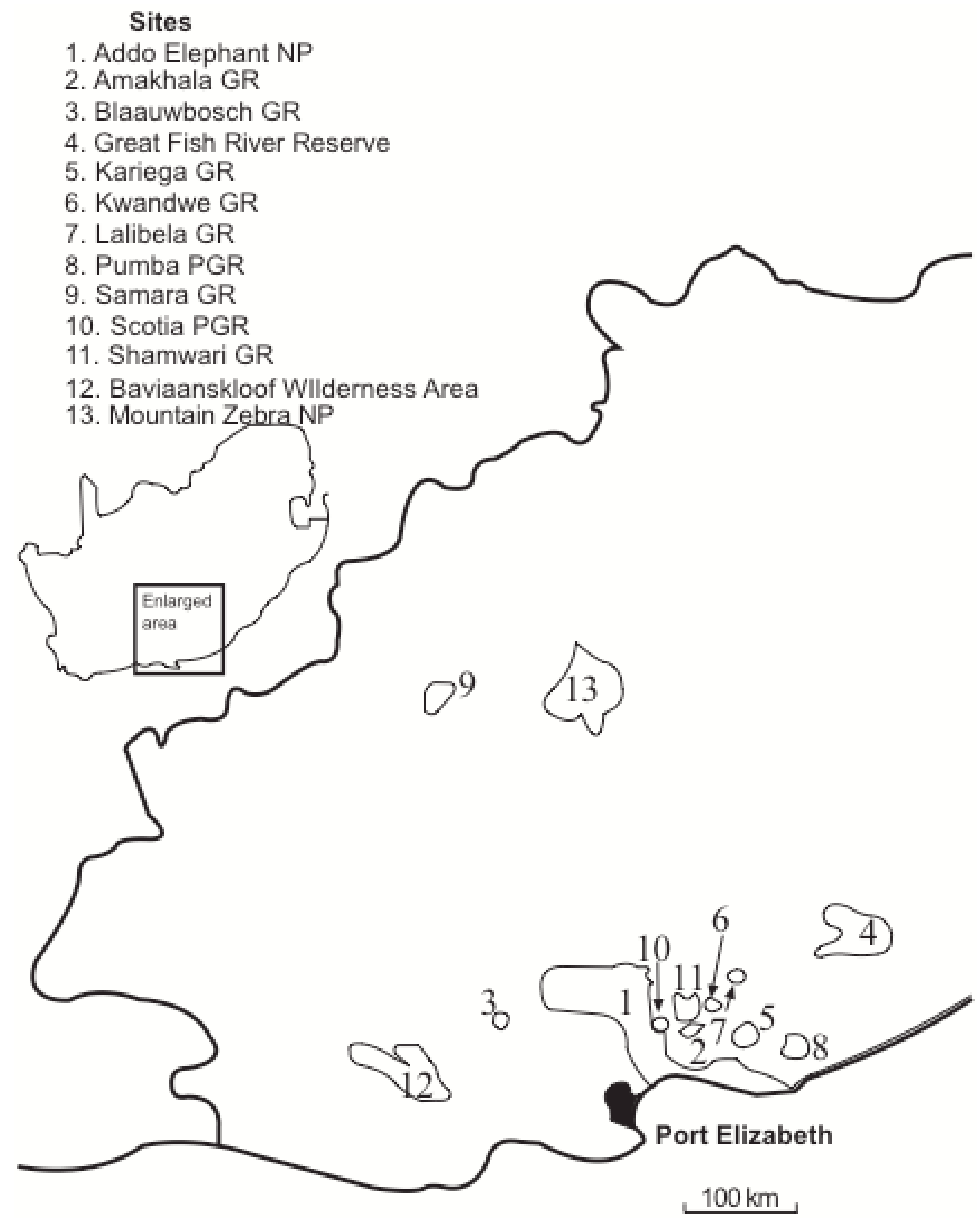

Fig. (1). Map of the Eastern Cape Province showing the location of the conservation areas discussed in the text. 
poorly understood to justify it as a conservation technique [3, 4]. Furthermore, carnivore reintroductions are considered fundamentally more difficult than those of herbivores or omnivores [12, 13]. The reintroduction of predators to South Africa's Eastern Cape Province has generally involved detailed monitoring. We define reintroduction as an attempt to establish a species within its historical range but from where it has been extirpated.

This paper reviews the causes of success and failure of the large $(>10 \mathrm{~kg})$ canid, felid and hyaenid reintroductions that have occurred in South Africa's Eastern Cape Province since 2000 (described in [9]). We report on the rationale behind the reintroductions, where the reintroduced stock was sourced from, pre- and post- release management, monitoring, costs and benefits of the reintroductions, and techniques to manipulate the behaviour of the large predators. Finally we discuss factors affecting our reintroduction success including genetics, habitat, causes of the initial decline, use of captive-bred stock, veterinary assistance, the economics of reintroduction, the value of fencing, the importance of monitoring and understanding a species behavioural ecology, the long-term evolutionary impacts of management, lessons learnt and the need to determine carrying capacity at reintroduction sites for large predators.

Given large carnivores are declining globally [14], identifying the successes and failures of reintroduction attempts is crucial to future conservation management efforts and overall conservation success. Ideally, this would be objectively assessed via statistical analysis (e.g., [15]). The short time frame since the reintroductions began in the Eastern Cape, and the small number of sites and species reintroduced restricted such analysis, particularly given Harrell's [16] 'rule of thumb' for regression models that a maximum of $n / 10$ explanatory variables can be used where $n$ is the number of observations (in this case 11 sites) [17]. Furthermore, some of the factors that are likely to have influenced the success of the reintroductions exhibited zero variability (e.g., all sites were fenced and all reintroductions were objectively classified as successful). An alternative analytical technique would be a meta-analysis (R. Slotow, pers comm.), however this requires the use of statistical effect and sample sizes from published sources, which are lacking. Hence, this review uses the expert opinion of the people charged with implementing or monitoring the reintroductions to identify and discuss the factors they considered to be important for the reintroduction of top-order predators.

\section{REINTRODUCTION SITES}

The large carnivore reintroductions reported on here occurred at 11 sites [9, 18] (Fig. 1). Data were collected from reintroduced animals via telemetry at Addo, Shamwari and Kwandwe, and intensive (twice daily) searches and incidental observations at each of these sites and by direct questioning of conservation managers, reserve owners and personal observations.

Like virtually all game reserves and national parks in South Africa, each reserve was enclosed with predator-proof, electrified fencing allowing them to be managed as distinct ecological units. They also each had electric fenced bomas to ensure a pre-release captivity period (soft-release). None of the sites allow hunting of large predators, and all obtain, at least, a large portion of their finances from ecotourism.

\section{REASONS FOR REINTRODUCING PREDATORS}

Clearly defined aims are essential for successful reintroduction [19], and in the Eastern Cape reserves these aims varied. The financial benefits arising from ecotourism drove the majority of reintroductions (Addo, Kariega, Kwandwe, Pumba, Scotia, Shamwari). The desire to provide tourists with a unique experience in the face of strong competition from other reserves has even led to captive-bred white lions being released in Pumba [9].

Several sites aimed to restore ecological integrity that would arise with an intact fauna (Addo, Kariega, Kwandwe, Pumba, Shamwari). Predators were also seen as performing a valuable management service by reducing the number of herbivores that were previously culled (Addo, Shamwari). Other sites also sought to actively conserve threatened or conservation-dependent species (Addo, Kwandwe, Shamwari).

\section{SOURCING PREDATORS FOR REINTRODUCTION}

The availability of animals to be reintroduced, their disease status and their genetic compatibility were influential in determining the source populations of reintroduced species and when they were released. Addo sourced their lions from the Kgalagadi Transfrontier Park, as the lions of the Kalahari were thought to be the most genetically similar extant population to the lions which originally occurred in the Eastern Cape, although there has been no study to prove this. The six founding lions were captured from widely separated areas and different prides to maximise genetic diversity, with nomadic females or males about to disperse being chosen to avoid disruption of the existing pride structure. Neither female was suckling when captured.

Shamwari sourced their lions from Madikwe and Pilanesberg because they were totally disease (tuberculosis and feline immunodeficiency virus) -free, like the Kalahari lions. As in Addo, each lion was captured from different prides to diversify the genetic base from which the founder population was created.

Kwandwe sourced some of their cheetahs from Phinda, where they occur in sympatry with lions [20]. Other cheetahs came from farmland in Limpopo, where they did not coexist with competitively superior species. The competitor-naïve cheetahs from farmland suffered a high mortality rate compared to the Phinda cheetahs (Fig. 4 in [9]) leading Kwandwe managers to conclude that cheetahs to be reintroduced alongside lions and spotted hyaenas are ideally obtained from areas where they coexist.

Leopards are difficult to successfully reintroduce for ecotourism purposes. Firstly, they tend to return to their original location (see review by [21]). Secondly, their secretive nature means they are rarely seen by tourists and occasionally escape to cause problems in adjacent pastoral areas. Shamwari sourced their leopard from rehabilitation centres where the 'wild edge' had been softened by exposure to veterinarians and carers. This has worked exceptionally well, with frequent sightings by tourists (leopards observed on 
$50 \%$ of days over 8 months to July 2006) [22] and the leopards have hunted independently since release [23].

\section{PRE-RELEASE MANAGEMENT}

All sites employed 'soft-release' techniques [24 p 306], where predators were kept in a boma for varying periods (Fig. 2). Boma construction is fundamental (see technical specifications in [25]) to ensure animals are exposed to electrified fencing, habituated to game viewing vehicles, allowed to settle, become accustomed to collars and other conspecifics within a new social group $[25,26]$ and ensure territorial bonds are relaxed so they remain at the release location [20, 27]. Bonding is not always successful however, and, in Welgevonden Private Game Reserve, a pride fragmented despite three months pre-release captivity [28].

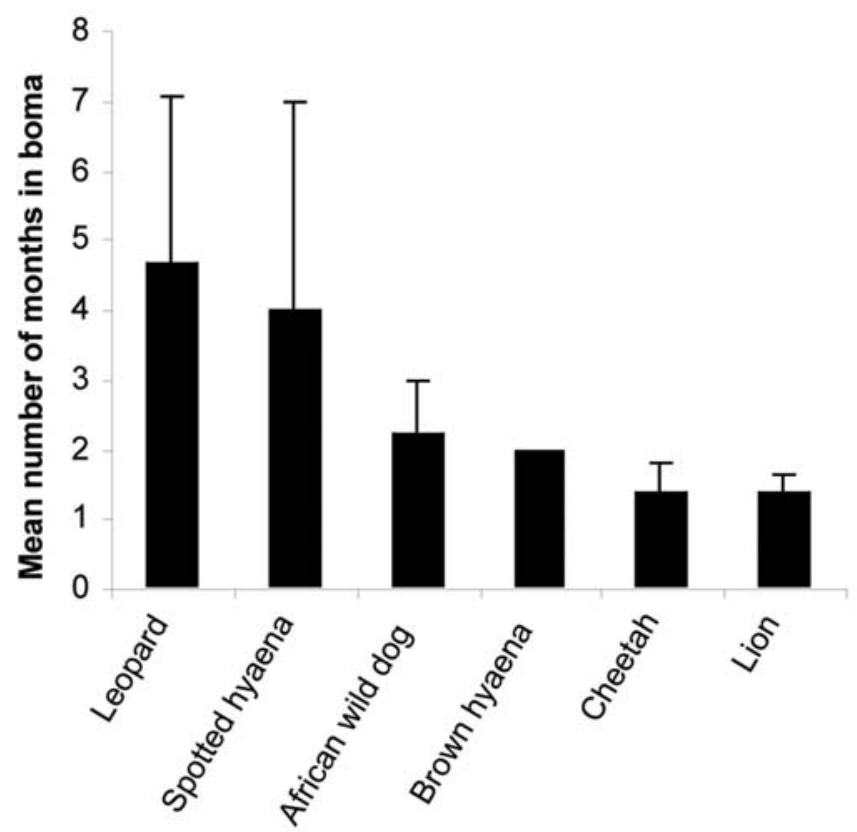

Fig. (2). Length of time each reintroduced carnivore species spent in an on-site, acclimatisation boma (mean months \pm 1 S.E.). The large S.E. for leopard stems from the escape of Addo's leopard within 24 hours of its soft release. Similarly, the long boma period for spotted hyaenas was due to disease testing.

Veterinary care can also be provided during the prerelease period, particularly internal and external parasite treatments, as increased parasite loads can occur in such stressful, captive situations [25]. This is also a time when individuals can be uniquely marked. While spot and coat patterns can assist in identifying individuals of several predator species (e.g. [29, 30]), this often requires intensive investigation and close proximity. Consequently, branding with unique line patterns, that end up looking like scars, can be used to identify individuals [20], although such wounds take a long time to heal [19]. Individuals can be marked when they are released or upon attaining independence.

At most Eastern Cape reintroduction sites, once the predators had settled within bomas, vehicles were left nearby with radios on and tourist game drives passed by in order to allow captive individuals to become accustomed to humans. Administering long-lasting sedatives can reduce aggression and speed bonding of non-related individuals in bomas [19, 20], however this strategy was only used at Kariega, where it was considered successful. Younger individuals also habituate faster than older ones [19].

The predators at Shamwari were always fed after a whistle was blown. This meant they associated the whistle with food and this has facilitated subsequent management activities. Cheetah, that were being restricted to a corner of the reserve by lions, were moved to more open habitat by following the whistle and a carcass dragged behind a vehicle. Shamwari's wild dogs and leopards have also been manipulated in this manner. Kwandwe managers also implemented this strategy with their wild dogs but have not had cause to use it.

The length of time individuals were kept in bomas varied amongst species and depended upon numerous factors (Fig. 2). Lions and cheetahs required the least amount of time in bomas (Fig. 2), although it is crucial that, like all predators, they develop an aversion to the electric fencing. For example, after two months in a boma, reintroduced lions at Phinda chased a zebra through the electrified boundary fence but failed to continue the chase past the fenceline despite the zebra's continued onward movement [20]. Conversely, driving prey through fences is a frequent cause of wild dog escapes and they place a great deal of pressure on fence infrastructure by using them to increase their hunting success [31, 32]. Cheetah have also been reported using fences to hunt [25].

Leopards tend to require the most time in bomas (Fig. 2), particularly where they are intended for ecotourism, so as to reduce their fear of humans and become less secretive. Leopards at Kwandwe and Shamwari were only released from the boma when they showed reduced levels of fear and could be manipulated for management activities. This strategy may increase the risk that these leopards could attack humans, as they may lack fear and wariness that would otherwise reduce such attacks.

African wild dogs also required a substantial period interned so that packs bond and develop a dominance hierarchy, particularly when individuals are not known to each other prior to capture. Without this, the pack is likely to fragment upon release and is then unlikely to breed [33, 34]. If unrelated individuals are to be combined into social groups (of wild dogs, lions, spotted hyaena or male cheetah), then the length of time in bomas may increase. Behavioural observations should be utilised to determine when groups are bonded and a dominance hierarchy has developed because the lack of social stability can lead to increased movements and mortality post-release $[35,36]$.

\section{POST-RELEASE MONITORING AND MANAGE- MENT}

It is universally recommended that continuing, long-term monitoring occur after reintroductions have taken place $[1,4$, $11,14,26]$. Despite such recommendations, not all reserves had specific monitoring programmes. Addo, Kwandwe and Shamwari have monitoring programmes run by trained ecologists, although not always full-time, permanent or longterm. Universities (Fort Hare, Nelson Mandela Metropolitan, Rhodes and Walter Sisulu) in the Eastern Cape have benefited from the expansion of game reserves with Addo, Kwandwe, Pumba and Shamwari coordinating research pro- 
jects through these institutions. In the Eastern Cape, monitoring often involved fitting radio telemetry collars or implants to all or some members of the reintroduced group and it has been suggested that monitoring with telemetry is likely to be necessary for up to 25 years post-release [1]. For those reserves that do monitor reintroduced animals, publication of the results of this research is only now beginning to occur [37, 38].

Reintroducing large predators to small, enclosed reserves is an intensive process and a great deal of management is required once they are released. The most common management activity after the release of lions is their removal after a rapid population increase. No lions were killed as part of these removals, and all removed individuals were used to restock other reserves.

Some animals have occasionally been supplementary fed following release. The lionesses at Addo were provided with culled warthog Phacochoerus africanus carcasses whilst they were struggling to keep young cubs alive. A female cheetah at Kwandwe was provided with carcasses when she was malnourished while raising four cubs.

Other interventions have occurred to provide veterinary care for wounded individuals. The alpha female wild dog at Shamwari was mauled by lions and was treated. An adult male lion at Addo had a large, gaping wound to his thigh stitched up while his collar was being removed. Such interventions are generally against the policies of each reserve, however the expenses associated with obtaining and reintroducing replacement animals are such that the survival of individuals is desirable. The wild dogs at Kwandwe were inoculated against rabies when their radio collars were refitted.

\section{COSTS AND BENEFITS OF REINTRODUCING PREDATORS}

Purchasing large predators for reintroduction is costly. Based on 2004 wildlife auction prices, when one South African Rand bought 0.16 US\$ (exchange rate @ 1/7/2004), buying individual cheetahs cost $\$ 2400$, hyaenas $\$ 800$, leopards and lions \$4000, and African wild dogs \$1280. Consequently, Shamwari housed $\$ 5,181,056$ worth of all wildlife, including $\$ 127,680$ in predators, and these predators killed $\$ 190,342$ worth of wildlife in 2004 of which impala $(\$ 60,800)$ and bushbuck $(\$ 29,200)$ were most costly. In 2004, Addo housed $\$ 12,148,600$ worth of wildlife of which buffalo Syncerus caffer comprised over $\$ 9.92$ million and predators accounted for $\$ 35,200$. Lions alone killed $\$ 473,984$ worth of wildlife in 2004 with buffalo $(\$ 441,487)$ and kudu $(\$ 14,235)$ forming the bulk of these costs. Similar calculations from Zimbabwe showed that ten lions killed US\$59,840 per year, but benefits through photographic safaris yielded a 10.4\% net benefit in 1995 [39]. Pilanesberg's lions were estimated to cost $\$ 160,000$ per annum but yielded $\$ 4,160,000$ in return [40].

This illustrates the value of reintroduction schemes being associated with ecotourism ventures where relocation costs can be rapidly erased. Elsewhere, where government-led programmes are more common, this is not the case and reintroductions involve substantial capital outlays with little opportunity of capital return [41].
Constructing and maintaining the infrastructure required to house large predators is also expensive (Fig. 3). Each of the Eastern Cape conservation areas has predator-proof boundary fences. The construction specifications of these fences is important (specifications described in $[19,26]$ ). Fences also require daily maintenance, although this can simultaneously fulfil valuable anti-poaching patrols.

Despite these costs, where data were available, it is financially beneficial to reintroduce large predators. Scotia estimated the reintroduction of lion led to a $\$ 320,000$ $\$ 640,000$ increase in turnover per annum. Shamwari saw a $31 \%$ increase in occupancy and a $71 \%$ increase in revenue following predator reintroduction.

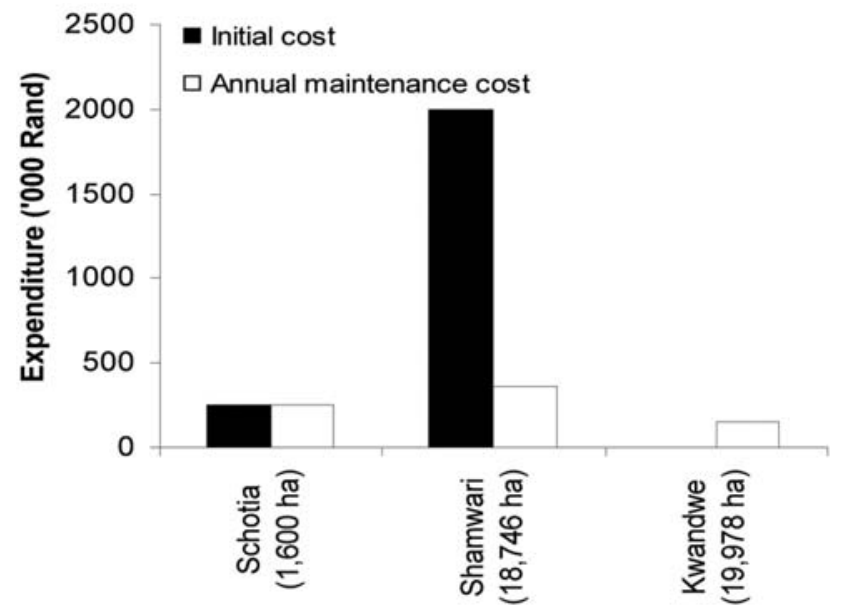

Fig. (3). Construction and maintenance costs of infrastructure necessary to house large reintroduced predators. Note that there were no additional construction costs to upgrade facilities to house predators at Kwandwe because it opened with large predators present.

\section{MANIPULATING PREDATORS}

The level of knowledge about the ecology of large predators in Africa is such that managers are now planning for various outcomes during the reintroduction process. Shamwari successfully employed this technique by housing two groups of three lions in separate bomas for two weeks to allow them to bond and create two separate prides upon release. Addo attempted a similar strategy with its lions, although upon release all but the sub-adult female joined together [37]. After six months, the males that were held in bomas together formed coalitions that fought for dominance and eventually established territories, however the females remained separate and non-territorial [37].

The prides at Shamwari, Kwandwe and Lalibela have been kept small, and male coalitions that were born and attained independence were moved to other reserves, to minimise the chances of large and valuable wildlife (buffalo and giraffe Giraffa camelopardalis) being killed. This may lead to evolutionary changes in both predator and prey however $[42,43]$.

\section{REINTRODUCTION SUCCESSES AND FAILURES}

Overall the reintroduction of large predators in the Eastern Cape was assessed as successful according to the available, relevant criteria [9] and, with economic forces driving the programme, it is unlikely that the reintroduction of such 
charismatic, tourist-attracting species will fail. Young have been observed for all reintroduced species, except leopard, and all populations have increased from the number initially reintroduced. Lions have rapidly become overabundant. Our data suggest that competitively dominant carnivores are more resilient to the reintroduction process than threatened species because they are free from competitive persecution. Despite this success, only lions are above the 50 breeding individuals considered necessary to protect from genetic problems [44] assuming occasional mixing of individuals between reserves. Consequently continued population supplementation and mixing of new genes will be fundamental to the long-term conservation of all species reported on here and therefore continued monitoring and management intervention will be necessary.

\section{FACTORS AFFECTING REINTRODUCTION SUC- CESS}

\section{Causes of Initial Local Extinction}

Another prerequisite for successful reintroduction is the elimination of the factors that initially caused the decline of the species [45, 46]. In the Eastern Cape these were predominately human persecution via hunting (both predator and prey), although the reduction of natural habitats through agriculture is also likely to have been important. Reintroduction sites in the Eastern Cape have each had some form of historical habitat disturbance, however their legislated protection as conservation estate affords both habitat and individuals safety. These sites are designed for ecotourism and, as such, have limited levels of hunting, as part of management activities to reduce herbivore overabundance.

\section{Presence of an Existing Population}

The presence of an existing population of a species may either positively or negatively affect the success of a reintroduction through attraction to a site or avoidance of it. For example, a lioness in oestrus was used to attract the other lions reintroduced to Matusadona National Park, Zimbabwe [47]. The hypothesized existing leopard populations in many Eastern Cape reserves prior to the reintroductions reported here [9] may supplement mortalities amongst the reintroduced stock. Conversely, breeding individuals in sites surrounding reintroduction sites may lead to escapes as reintroduced individuals seek off-site mating opportunities. The ability of leopards to cross fences suggests they are most susceptible to such problems. Similarly, existing populations of spotted hyaenas at Madikwe Game Reserve, South Africa, killed a clan that were reintroduced [26]. The presence of an existing population is considered a factor contributing to the failure of some reintroduction programmes [12].

\section{Fencing}

The success of reintroductions in South Africa is largely due to fencing [15], which minimises negative humanwildlife interactions and provides assured ownership of valuable wildlife capital. In an ideal world, fencing conservation areas would be unnecessary and wildlife could roam wherever it chose, however most conservation areas worldwide today are natural islands in a matrix of disturbed environments [48]. Hence it soon may be necessary to fence all wildlife conservation areas or sections of them where wildlife and humans may interact negatively.
The value of fencing conservation reserves, or even core areas of reserves, to reduce encroachment, negative humanwildlife interactions or the effects of unwanted species (exotics, etc.) cannot be understated. Even in Kenya's Laikipia ranches, where researchers have been devising methods to reduce the impacts of wildlife-human interactions [49], fences have been recommended as ways of reducing negative impacts [50]. Clearly, the placement of fences is critical and must consider the behaviour and ecology of the species present in a reserve rather than human interests (e.g. [51]).

\section{Habitat Features}

There are numerous other factors that have previously been identified as important to the success of reintroductions. The principal cause of most species' decline is the loss and alteration of habitat $[45,52]$. For large carnivores this is less likely than for other species, as prey availability is more important than the vegetation characteristics of a site [42, 53, 54]. Hence, if there is suitable prey available [23, 55-58], adequate refuges for competitively-inferior predators to escape persecution and kleptoparasitism from larger predators [59] and measures to alleviate human - wildlife conflict [15], then all large predator reintroductions are likely to be successful. Each of the sites in the Eastern Cape has properly reserved habitat and adequate food availability. Furthermore, socio-political factors are directing the reintroductions in the Eastern Cape, because there is a substantial economic benefit to conserve land, protect and improve habitats which is likely to increase wildlife carrying capacity and thereby sustain increased predator density $[60,61]$.

\section{Captive-Bred Stock}

Reintroduction of captive-bred mammals has also been doomed by poor techniques preparing captive animals for survival in the wild [45]. While the reintroduction of captivebred African wild dogs in Etosha in the 1990s failed because the could not hunt successfully [62], mixing captive-bred and wild caught African wild dogs is a common method today $[26,33]$ and is highly successful at teaching captive-bred individuals how to hunt and socialise appropriately.

\section{Social Group Composition}

An appropriate mix of individuals in a social group is an important consideration in reintroductions [45]. Large social predators seem resilient to interactions with unrelated and unknown individuals when kept for long periods in captive situations [33, 36], particularly when sedatives are given during the initial, high-stress phase of the boma period.

The choice of group composition for the Addo lion reintroduction illustrates the depth of knowledge South African wildlife managers have developed, yet lessons have been learned from this. Four males and two females is atypical in terms of lion pride structure [63], however the size of Addo's Main Camp section (13,400 ha) was considered too small for large numbers of lion [53] and so managers hoped infanticide by unrelated male lions [64] and predation of cubs by spotted hyaenas would slow the population increase. This has worked to date, with three of four litters failing.

\section{Veterinary Assistance}

Disease can hamper reintroduction attempts [34, 62], however as few as $24 \%$ of reintroduction programs utilise 
veterinary screening [12]. Therefore involving veterinarians is crucial. Several of the Eastern Cape conservation areas have such experts on staff (e.g. Addo - South African National Parks; Amakhala; Shamwari) and there is a large industry in South Africa of wildlife relocation companies that also have veterinarians experienced in treating large species.

\section{Economics}

Costs can inhibit wildlife reintroduction [45], however in areas where wildlife has an economic value, this value generally drives their reintroduction. This is particularly the case in South Africa where government conservation agencies and private companies have experts in the capture and movement of animals, such that translocation is relatively safe and cheap. Subsequently, the desires of tourists drive the reintroduction of charismatic species, especially large predators [25], which concomitantly protects habitat [60].

\section{Genetics}

Carnivore reintroductions typically involve small founder populations so that genetic problems may become an issue. The original lions in the Eastern Cape were thought to be genetically similar to Kalahari lions and only Addo reintroduced these. It may be worthwhile using excess lions from Addo to increase genetic diversity at other sites with the longer-term aim of converting all Eastern Cape lions to something akin to the Kalahari strain. Such hybrid matings among different populations may allow natural selection to produce a 'locally-adapted' genotype [13].

A studbook needs to be created and maintained for this to be successful. Given the likelihood of moving individuals between reserves, this studbook should also direct the shapes of identification brands (if they are used) to avoid duplication of marks between sites. Furthermore, genetic analysis should be conducted to ensure related individuals are identified prior to movement between sites.

\section{Evolutionary Impacts of Management Actions}

Another issue that must be considered, with regard to the level of management required in small, enclosed reserves, is that management actions may lead to evolutionary responses. Coalitions of male lions have been removed at several sites, however this may mean that the anti-predator strategy of large prey species, like buffalo and giraffe, becomes redundant and may weaken the herd via the retention of genes that would otherwise have been selected out of the population. Conversely it seems unlikely that such management will result in an alteration of the lions' predatory instinct given that those reintroduced to Addo from the buffalo-free Kalahari took less than one year to learn how to hunt buffalo successfully [42]. Even the frequent management practice of maintaining coalitions of male lions is unusual in more natural ecosystems where coalition sizes range up to nine [65]. Consequently, cognisance must be given to allowing evolutionary processes to continue.

\section{LESSONS LEARNT}

Competitively subordinate and vulnerable carnivores should be released prior to dominant species. This is probably because these more sensitive species need to locate refugia [59] before the arrival of potential competitors and predators. This rarely happened in the Eastern Cape game reserves and may explain the limited success of cheetah reintroductions [9].

Shamwari managers considered it a mistake, in retrospect, to release cheetahs sequentially. They believe their cheetahs would have adapted better if they were reintroduced simultaneously in larger numbers. Also, the large male cheetah coalition at Kwandwe has been problematic through attacks on conspecifics.

All reserves recognised the importance of soft-release techniques [34]. The location and construction of pre-release housing bomas has caused problems however. These should be constructed so that free-ranging predators cannot harass those awaiting release. Such harassment led to a male cheetah being killed by a female leopard at Shamwari, and was regularly observed at Addo when the dominant lion coalition harassed (roared, charged the fence, scent marked all around the boma) the captive hyaenas.

Whilst in the boma, it is important that lions or leopards do not learn to associate humans with food. Consequently, they were fed either remotely or from concealed positions, such as via pulley-systems that deposited carcasses over the boma fence or through a shute while the human operators were concealed from view (see [19] for specifications).

A sound relationship with adjacent land owners is also an important consideration. Consultation and cooperation is crucial in this regard. Educating and training staff is also critical to minimise the chance of accidents.

\section{CARRYING CAPACITY FOR LARGE PREDATORS}

There appears to be a deficiency in knowledge about the carrying capacity at each site for each predator. Managers of each reserve have an idea of how many individuals of each species they desire on their reserve (Fig. 4), but there is no scientific rationale behind this. Recent research may be able to provide estimates however [53]. Overpopulation of a predator can result in escapes [66] and this is a problem even in large conservation areas, like the Kgalagadi Transfrontier Park [67]. Frequent observations of individuals along boundary fences may be indicative that carrying capacity (ecological and/or social) has been exceeded (e.g. [25]).

Currently the reserves are battling with what to do with excess large predators, particularly lions. To date, excess individuals from truly free-range sites have generally been removed to restock newer reserves. This practice has been employed elsewhere and in Phinda excess lions and cheetahs were removed within three years of the reintroduction due to declines in prey species [20]. This option is rapidly running out and new avenues of population control, such as contraception [68] or sterilization of certain individuals, are being sought. Yet this raises May's [13] ethical quandary as to "what extent does this preserve the African lion with its diverse array of individual and group behaviour", even if the species still survives? National parks and many Eastern Cape reserves are averse to incorporating hunting of excess predators into their management regimes because of the bad publicity they will derive from tourists and the animal welfare lobby, despite the potential income benefits $[69,70]$. The misdirected power of these groups is evidenced by the cessation of elephant Loxodonta africana culling in South African national parks [71]. 


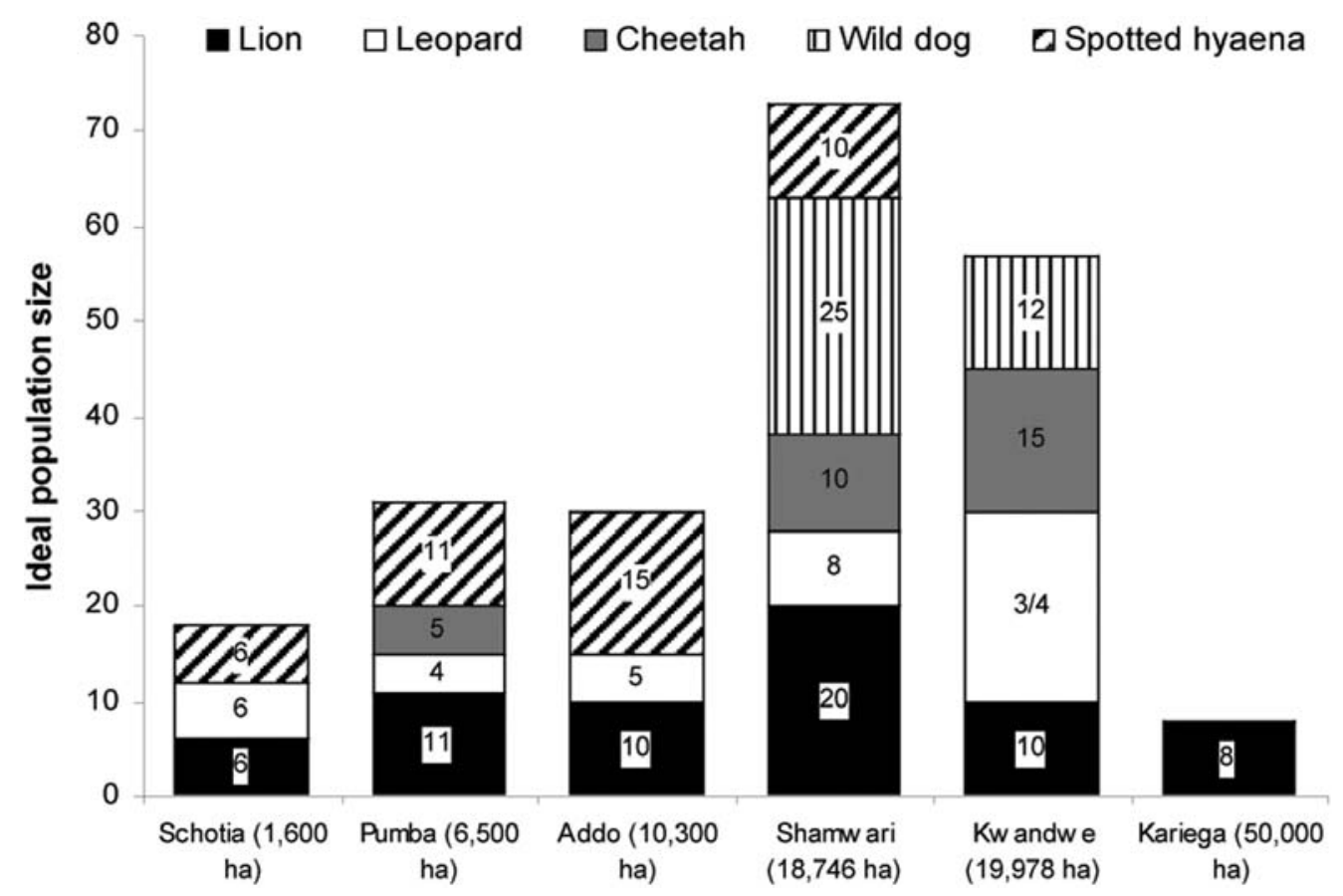

Fig. (4). Estimates of the carrying capacity of large predators at each reserve made by their conservation managers.

\section{CONCLUSIONS}

Where reviews a decade ago concluded that reintroductions of large predators were not viable [3,4], an increase in knowledge and technical improvements since has made it common practice [9]. Management is a permanent requirement for the conservation of large, terrestrial predators in all but the largest conservation areas [9] and for those inherently rare species [72]. The impact of these species on prey populations in small, enclosed areas and the potential for loss of genetic diversity will necessitate frequent monitoring and intervention for the foreseeable future. One option available to clumps of private conservation areas, such as many of those in the Eastern Cape, is to join together as a conservancy, which would retain individual tourist ventures while allowing for the removal of internal fences resulting in one large conservation unit. This would substantially reduce management costs and allow evolutionary processes to continue [9]. Without this, the value of these reintroductions into small isolated reserves for the conservation of threatened species is questionable [5].

\section{ACKNOWLEDGEMENTS}

MWH thanks Gina Hayward for running the Addo Predator Reintroduction Research Project (SAN Parks Approval No. 2004-03-01GKER) which was funded by the Nelson Mandela Metropolitan University, the National Research Foundation, Budget Rent-a-Car, Eveready Batterys, C.R. Kennedy P/L, Leica, and Continental. This manuscript has been improved by reviews from Martin Fisher, Michael Somers, Rob Slotow, Dave Druce and Ben Russell.

\section{REFERENCES}

[1] Breitenmoser U, Breitenmoser-Wursten C, Carbyn LN, Funk SM. Assessment of carnivore reintroductions. In: Carnivore Conservation. Edited by Gittleman JL, Funk SM, Macdonald DW, Wayne RK. Cambridge, UK: Cambridge University Press and The Zoological Society of London; 2001; 241-280.
[2] Panwar HS, Rodgers WA. The reintroduction of large cats into wildlife protected areas. Indian Forestor 1986; 112: 939-944.

[3] Wemmer C, Sunquist ME. Felid reintroductions: economic and energetic considerations. In: Proceedings of the 5th International Snow Leopard Symposium. Edited by Freeman H. Delhi, India: International Snow Leopard Trust \& The Wildlife Institute India; 1988; 193-205.

[4] Mills MGL. Conservation management of large carnivores in Africa. Koedoe 1991; 34(1): 81-90.

[5] Hunter LTB, Pretorius K, Carlisle LC, et al. Restoring lions Panthera leo to northern KwaZulu-Natal, South Africa: short-term biological and technical success but equivocal long-term conservation. Oryx 2007; 41: 196-204.

[6] Seddon PJ, Soorae PS, Launay F. Taxonomic bias in reintroduction projects. Anim Conserv 2005; 8: 51-58.

[7] Skead CJ. Historical Mammal Incidence in the Cape Province. Volume 2: The Eastern Half of the Cape Province, including the Ciskei, Transkei and East Griqualand. Cape Town: Chief Directorate Nature and Environmental Conservation of the Provincial Administration of the Cape of Good Hope, South Africa.; 1987.

[8] Kerley GIH, Boshoff AF. A Proposal for a Greater Addo National Park: a regional and national conservation and development opportunity. In. Port Elizabeth: Terrestrial Ecology Research Unit, Department of Zoology, University of Port Elizabeth; 1997: 1-63.

[9] Hayward MW, Adendorff J, O'Brien J, et al. The reintroduction of large predators to the Eastern Cape Province, South Africa: an assessment. Oryx 2007; 42(1): 205-214.

[10] Kleiman DG, Reading RP, Miller BJ, et al. Improving the evaluation of conservation programs. Conserv Biol 2000; 14(2): 356-365.

[11] Hunter LTB. Early post-release movements and behaviour of reintroduced cheetahs and lions, and technical considerations in large carnivore restoration. In: Cheetahs as Game Ranch Animals. Edited by Penzhorn BL. Onderstepoort, South Africa.: Wildlife Group of the South African Veterinary Association; 1998; 72-82.

[12] Griffith B, Scott JM, Carpenter JW, Reed C. Translocation as a species conservation tool: status and strategy. Science 1989; 245: 477-480.

[13] May RM. The role of ecological theory in planning re-introduction of endangered species. Symp Zool Soc Lond B 1991; 62: 145-163.

[14] Weber W, Rabinowitz A. A global perspective on large carnivore conservation. Conserv Biol 1996; 10(4): 1046-1054.

[15] Gusset M, Ryan SJ, Hofmeyr M, et al. Efforts going to the dogs? Evaluating attempts to re-introduce endangered wild dogs in South Africa. J Appl Ecol 2007; In press: doi 10.1111/j.13652664.2007.01357.x. 
[16] Harrell FE. Regression Modeling Strategies: with applications to linear models, logistic regression and survival analysis. New York: Springer; 2001.

[17] Hayward MW, de Tores PJ, Dillon MJ, Banks PB. Predicting the occurrence of the quokka, Setonix brachyurus (Macropodidae: Marsupialia), in Western Australia's northern jarrah forest. Wildl Res 2007; 34(3): 194-199.

[18] Hayward MW, Adendorff J, O'Brien J et al. The reintroduction of large carnivores to the Eastern Cape, South Africa: an assessment [Erratum]. Oryx 2007; 41(3): 413 doi:410.1017/S0030605307001 962.

[19] van Dyk G. Reintroduction techniques for lion (Panthera leo). In: Lions and Leopards as Game Ranch Animals. Edited by Penzhorn BL. Onderstepoort, South Africa: SAWVA; 1997; 82-91.

[20] Hunter LTB. The Behavioural Ecology of Reintroduced Lions and Cheetahs in the Phinda Resource Reserve, kwaZulu-Natal, South Africa. Ph.D. thesis. University of Pretoria; 1998.

[21] Hayward MW, Adendorff J, Moolman LC, Hayward GJ, Kerley GIH. The successful reintroduction of leopard Panthera pardus to the Addo Elephant National Park. Af J Ecol 2007; 45(1): 103-104.

[22] Shamwari Game Reserve Animal Sightings Webpage, Shamwari, South Africa, Available at http://www.shamwari.co.za

[23] Hayward MW, Henschel P, O'Brien J, Hofmeyr M, Balme G, Kerley GIH. Prey preferences of the leopard (Panthera pardus). J Zool 2006; 270: 298-313 doi:210.1111/j.1469-7998.2006.00139.x.

[24] Caughley G, Gunn A. Conservation biology in theory and practice. Carlton, Victoria: Blackwell Science; 1996.

[25] Hofmeyr M, van Dyk G. Cheetah introductions to two north-west parks: case studies from Pilanesburg National Park and Madikwe Game Reserve. In: Cheetahs as Game Ranch Animals. Edited by Penzhorn BL. Onderstepoort, South Africa.: Wildlife Group of the South African Veterinary Association; 1998; 60-71.

[26] Hofmeyr M, Davies R, Nel P, Dell S. Operation Phoenix - the introduction of larger mammals to Madikwe Game Reserve. In: Madikwe Game Reserve: a Decade of Progress. Edited by Brett M. Rustenberg, South Africa: North West Parks \& Tourism Board; 2003; 8-20.

[27] Linnell JDC, Odden J, Smith ME, Aanes R, Swenson JE. Translocation of carnivores as a method for problem animal management: a review. Biodiv Conserv 1997; 6: 1245-1257.

[28] Killian PJ, Bothma JdP. Notes on the social dynamics and behaviour of reintroduced lions in the Welgevonden Private Game Reserve. SA J Wildl Res 2003; 33(2): 119-124.

[29] Pennycuick CJ, Rudnai J. A method of identifying individual lions Panthera leo with an analysis of the reliability of identification. J Zool 1970; 160: 497-508.

[30] Kelly MJ. Computer-aided photograph matching: an example of Serengeti cheetahs. Cat News 2001; 34: 29-30.

[31] van Dyk G, Slotow R. The effects of fences and lions on the ecology of African wild dogs reintroduced to Pilanesberg National Park, South Africa. Af Zool 2003; 38(1): 79-94.

[32] Rhodes R, Rhodes G. Prey selection and use of natural and manmade barriers by African wild dogs while hunting. SA J Wildl Res 2004; 34(2): 135-142.

[33] Graf JA, Gusset M, Reid C, Janse van Rensburg S, Slotow R, Somers MJ. Evolutionary ecology meets wildlife management: artificial group augmentation in the re-introduction of endangered African wild dogs (Lycaon pictus). Anim Conserv 2006; 9: 398-403.

[34] Moehrenschlager A, Somers MJ. Canid reintroductions and metapopulation management. In: Canids: Foxes, Wolves, Jackals and Dogs. Status Survey and Conservation Action Plan. Edited by Sillero-Zubiri C, Hoffman M, Macdonald DW. Gland, Switzerland and Cambridge, UK.: IUCN/SSC Canid Specialist Group; 2004; 289-298.

[35] Stander PE. A suggested management strategy for stock-raiding lions in Namibia. SA J Wildl Res 1990; 20: 37-43.

[36] Gusset M, Slotow R, Somers MJ. Divided we fail: the importance of social integration for the re-introduction of endangered wild dogs (Lycaon pictus). J Zool 2006; 270: 502-511.

[37] Hayward MW, Hayward GJ. Activity patterns of reintroduced lion Panthera leo and spotted hyaena Crocuta crocuta in Addo Elephant National Park, South Africa. Af J Ecol 2007; 45: 135-141 doi: 110.1111/j.1365-2028.2006.00686.x.

[38] Bissett C, Bernard RTF. Habitat selection and feeding ecology of the cheetah (Acinonyx jubatus) in thicket vegetation: is the cheetah a savanna specialist? J Zool 2007; 271: 310-317.
[39] Cotterill A. The economic viability of lions (Panthera leo) on a commercial wildlife ranch: examples and management implications for a Zimbabwean case study. In: Lions and Leopards as Game Ranch Animals. Edited by Penzhorn BL. Onderstepoort, South Africa: SAVWA; 1997; 189-197.

[40] Stuart-Hill G, Grossman D. Parks, profits and professionalism: lion return to Pilanesberg. African Wildlife 1993; 47(5): 267-280.

[41] Yalden D. The problems of reintroducing carnivores. Symp Zool Soc Lond B 1993; 65: 289-306.

[42] Hayward MW, Hofmeyr M, O'Brien J, Kerley GIH. Testing predictions of the prey of the lion (Panthera leo) derived from modelled prey preferences. J Wildl Manag 2007; 71(5): 1567-1575.

[43] Crandall KA, Bininda-Emonds ORP, Mace GM, Wayne RK. Considering evolutionary processes in conservation biology. Trends in Research of Ecology and Evolution 2000; 15: 290-295.

[44] Frankham R. Genetics and evolution. Biol Conserv 2005; 126: 131 140 .

[45] Kleiman DG. Reintroduction of captive mammals for conservation. BioScience 1989; 39(3): 152-161.

[46] Caughley G. Directions in conservation biology. J Anim Ecol 1994; 63: 215-244.

[47] Hoare RE, Williamson J. Assisted re-establishment of a resident pride of lions from a largely itinerant population. SA J Wildl Res 2001; 31: 179-182.

[48] Saunders DA, Hobbs RJ, Margules CR. Biological consequences of ecosystem fragmentation: a review. Conserv Biol 1991; 5(1): 1832.

[49] Ogada MO, Woodroffe R, Oguge NO, Frank LG. Limiting depredation by African carnivores: the role of livestock husbandry. Conserv Biol 2003; 17(6): 1521-1530.

[50] Thouless CR, Sakwa J. Shocking elephants: fences and crop raiders in Laikipia District, Kenya. Biol Conserv 1995; 72: 99-107.

[51] Child G. Observations on a wildebeest die-off in Botswana. Arnoldia 1972; 31: 1-13.

[52] Diamond JM. Overview of recent extinctions. In: Conservation for the Twenty-first Century. Edited by Western D, Pearl MC. New York, USA: Wildlife Conservation International, New York Zoological Society; 1989; 37-54.

[53] Hayward MW, O'Brien J, Kerley GIH. Carrying capacity of large African predators: predictions and tests. Biol Conserv 2007; 139: 219-229.

[54] Karanth KU, Nichols JD, Kumar NS, Link WA, Hines JE. Tigers and their prey: predicting carnivore densities from prey abundance. Proc Natl Acad Sci 2004; 101: 4854-4858.

[55] Hayward MW. Prey preferences of the spotted hyaena Crocuta crocuta and evidence of dietary competition with lion Panthera leo. J Zool 2006; 270: 606-614 DOI: 610.1111/j.1469-7998. 2006.00184.x.

[56] Hayward MW, Hofmeyr M, O'Brien J, Kerley GIH. Prey preferences of the cheetah Acinonyx jubatus: morphological limitations or the need to capture rapidly consumable prey before kleptoparasites arrive? J Zool 2006; 270: 615-627 DOI: 610.1111/j.14697998.2006.00184.x.

[57] Hayward MW, Kerley GIH. Prey preferences of the lion (Panthera leo). J Zool 2005; 267(3): 309-322 doi:310.1017/S095283690500 7508.

[58] Hayward MW, O'Brien J, Hofmeyr M, Kerley GIH. Prey preferences of the African wild dog Lycaon pictus: ecological requirements for their conservation. J Mammal 2006; 87(6): 1122-1131.

[59] Durant SM. Competition refuges and coexistence: an example from Serengeti carnivores. J Anim Ecol 1998; 67: 370-386.

[60] Hayward MW. Lessons from South Africa. Nature Aust 2005; 28(6): 80 .

[61] Lindsey PA, Alexander R, du Toit JT, Mills MGL. The cost efficiency of wild dog conservation in South Africa. Conserv Biol 2005; 19(4): 1205-1214.

[62] Scheepers JL, Venzke KAE. Attempts to reintroduce African wild dogs Lycaon pictus into Etosha National Park, Namibia. SA J Wildl Res 1995; 25(4): 138-140.

[63] Schaller GB. The Serengeti Lion. Chicago: University of Chicago Press; 1972.

[64] Packer C, Pusey AE. Adaptations of female lions to infanticide by incoming males. Am Nat 1983; 121(5): 716-728.

[65] Packer C, Pusey AE. Cooperation and competition within coalitions of males lions: kin selection or game theory? Nature 1982; 296: 740-742. 
[66] Maddock A, Anderson A, Carlisle F, et al. Changes in lion numbers in Hluhluwe-Umfolozi Park. Lammergeyer 1996; 44: 6-18.

[67] Castley JG, Knight MH, Mills MGL, Thouless CR. Estimation of the lion (Panthera leo) population in the southwestern Kgalagadi Transfrontier Park using a capture-recapture survey. Af Zool 2002; 37(1): 27-34.

[68] Orford HJL, Perrin MR. Contraception, reproduction and demography of free-ranging Etosha lions ( Panthera leo ). J Zool 1988; 216 : 717-733.

[69] Lindsey PA, Alexander R, Frank LG, Mathieson A, Romanach SS. Potential of trophy hunting to create incentives for wildlife conservation in Africa where alternative wildlife-based land uses may not be viable. Anim Conserv 2006; 9: 283-291.

Received: November 26, 2007

Revised: December 13, 2007

Accepted: December 15, 2007
[70]

Lindsey PA, Frank LG, Alexander R, Mathieson A, Romanach SS. Trophy hunting and conservation in Africa: problems and one potential solution. Conserv Biol 2007.

[71] Owen-Smith N, Kerley GIH, Page B, Slotow R, Van Aarde RJ. A scientific perspective on the management of elephants in the Kruger National Park and elsewhere. SA J Sci 2006; 102: 389-394.

[72] Creel S, Spong G, Creel NM. Interspecific competition and the population biology of extinction-prone carnivores. In: Carnivore Conservation. Edited by Gittleman JL, Funk SM, Macdonald DW, Wayne RK. Cambridge: Cambridge University Press and The Zoological Society of London; 2001; 35-60. 